\title{
Inadequate symptom control in advanced cancer patients across Europe
}

\author{
Eivor A. Laugsand • Gunnhild Jakobsen • Stein Kaasa • \\ Pål Klepstad
}

Received: 28 April 2010 / Accepted: 14 November 2010 /Published online: 30 November 2010

(C) The Author(s) 2010. This article is published with open access at Springerlink.com

\begin{abstract}
Purpose The purpose of this study is to examine the adequacy of treatment for constipation, nausea, depression and poor sleep and the factors associated with inadequate symptom control in cancer patients receiving opioids.

Methods Patients receiving strong opioids for cancer pain were recruited from 17 centres in 11 European countries. By using the European Organization for Research and Treatment of Cancer Core Quality of Life Questionnaire C30, 1,938 patients reported their symptoms at four-point scales. Health care providers assessed symptoms at corresponding four-point scales and registered use of medications, demographic and disease-related variables. Symptomatic treatment was scored as 1 if not administered during the past $24 \mathrm{~h}$ and as 2 if administered. Adequacy of treatment was evaluated by subtracting the patients'
\end{abstract}

E. A. Laugsand $(\bowtie) \cdot$ G. Jakobsen $\cdot$ S. Kaasa

Department of Cancer Research and Molecular Medicine,

Faculty of Medicine,

Norwegian University of Science and Technology (NTNU),

Medisinsk teknisk forskningssenter, Olav Kyrres gate 9,

7489 Trondheim, Norway

e-mail: eivor.a.laugsand@ntnu.no

S. Kaasa

Department of Oncology, St. Olav University Hospital,

7006 Trondheim, Norway

\section{P. Klepstad}

Department of Circulation and Medical Imaging,

Faculty of Medicine,

Norwegian University of Science and Technology (NTNU),

7489 Trondheim, Norway

P. Klepstad

Department of Anaesthesiology and Emergency Medicine,

St. Olav University Hospital,

7006 Trondheim, Norway symptom score from the treatment score. Negative scores, caused by either no treatment or ineffective treatment of a symptom, were interpreted as inadequate treatment.

Results Approximately $60 \%$ of patients with constipation, depression or poor sleep and $45 \%$ of nauseated patients were inadequately treated. Numbers of inadequately treated patients varied between countries. In general, underestimation of symptom intensity by health care providers $(p<$ $0.001)$, low performance status $(p<0.05)$ and recent initiation of opioids $(p<0.05)$ increased the risk of inadequate treatment. The subset of demographic- and disease-related factors associated with inadequate treatment varied between the symptoms investigated.

Conclusions Inadequate treatment, either no treatment or ineffective treatment, was frequent in cancer patients. There were subgroups of patients at particular risk for inadequate treatment, which might need additional attention from health care providers for achievement of adequate symptom control.

Keywords Constipation · Nausea · Depression · Sleep · Opioid · Palliative care

\section{Introduction}

Constipation, nausea, depression and poor sleep are frequent symptoms among patients with advanced cancer $[1,2]$. Several guidelines, mostly based on aggregated clinical experience and expert recommendations, describe how to treat symptoms in cancer patients [3-7]. Still, symptoms like constipation, nausea, depression and poor sleep are often inadequately treated [2, 7-10]. There are inter-individual variations in both symptom susceptibility and treatment response among cancer patients, but little is 
known about which patients are at risk for inadequate treatment.

Constipation affects at least $30-50 \%$ of cancer patients $[4,8]$. Guidelines emphasize the importance of regularly prescribed laxatives for patients treated with opioids [3, 4], but up to $90 \%$ are inadequately treated [1, 8]. Opioids induce nausea in nearly $40 \%$ of patients [3]. The recommended treatment is antiemetic drugs directed to the underlying pathophysiological mechanism, although this strategy often fails $[3,5,9,11]$. Depression is found in about half of advanced cancer patients [12]. Evidence supports treating cancer-associated depression with psychotherapy, tricyclic antidepressants or selective serotonin reuptake inhibitors [6]. Still, only a minority of depressed patients with advanced cancer are treated with antidepressants $[6,10]$. If asked, most cancer patients report poor sleep [13]. Removal of underlying physical and psychological factors as well as a hypnotic agent is usually needed to treat poor sleep [7, 13]. However, poor sleep is often neither recognized nor treated among patients with cancer [7].

The inter-individual variations in symptom susceptibility and treatment response may be related to demographic- and disease-related factors, to differences in definition, assessment and treatment of symptoms [14]. To improve symptom control in cancer patients, current practice and adequacy of treatment needs to be assessed [15]. Inadequately treated patients should be identified and characterized. To date, there is no agreement on how to evaluate inadequate treatment of constipation, nausea, depression and poor sleep. Three studies have identified inadequate treatment of symptoms in cancer patients $[8,9,16]$. For pain, variants of the pain management index (PMI) have been used for assessment of the relationship between symptom intensity and adequacy of treatment [17-19]. In the present study, the relationship between symptom intensity and treatment was utilized to (1) examine the adequacy of treatment for constipation, nausea, depression and poor sleep, and to (2) examine whether demographicand disease-related factors are associated with inadequate control of these symptoms.

\section{Methods}

\section{Patients}

Between February 2004 and April 2008, 2,294 cancer patients from 17 centres in 11 European countries were included in the cross-sectional European Pharmacogenetic Opioid Study. Patients were18 years old or more, had a verified malignant disease and were treated for at least 3 days with a scheduled opioid corresponding to the World
Health Organization's (WHO) analgesic ladder step III for cancer pain. Patients were excluded if not proficient in the language of the study centre. Three hundred and fifty-six patients did not give self-report of symptoms because they were too ill $(48 \%)$, did not want to complete the questionnaire $(40 \%)$ or for unknown reasons $(12 \%)$. Accordingly, 1,938 patients completed the symptom assessments and were included in the analyses.

\section{Ethics}

The study was performed in accordance with the Declaration of Helsinki. Each country's or study centre's ethical committee approved the study. Each patient gave written informed consent before inclusion.

\section{Data collection}

Health care providers (physician or nurse) registered patient characteristics: age, weight, height, time since diagnosis (months), time since start of opioids (months), gender, status of opioid treatment (recently initiated and still under titration or stable dosing), department (hospitalized or outpatient), previous abuse of alcohol and/or drugs (yes or no), metastases and cancer diagnosis. The mini mental state (MMS) examination was performed to identify cognitive failure (total score of 23 or less) [20,21]. Functional status was assessed by the Karnofsky performance status [22]. The use of all medications during the past $24 \mathrm{~h}$ (including opioids and chemotherapy) were obtained from the patients' medical records. Providers also assessed constipation, nausea, depression and poor sleep during the past $24 \mathrm{~h}$ on four-point verbal rating scales with the descriptors none (1), mild (2), moderate (3) and severe (4). By using the European Organization for Research and Treatment of Cancer Core Quality of Life Questionnaire C30 (EORTCQLQ-C30) version 3.0, the same symptoms were reported by patients on corresponding four-point scales for the past week on average [23].

Data analysis

Administration of medications is presented as absolute numbers and percentages of untreated and treated patients. Mann-Whitney $U$ tests were performed to investigate whether the numbers of untreated and treated patients varied in relation to symptom intensity.

To examine the adequacy of symptomatic treatment, an approach utilizing the relationship between symptom intensity and treatment was used. This strategy was based upon three previous studies describing adequacy of symptomatic treatment in cancer patients $[8,9,16]$ and a validated method for assessing the adequacy of cancer pain 
treatment, the PMI [17-19]. Treatment was scored as 1 if no drug was administered and as 2 if a drug was administered for symptom control during the past $24 \mathrm{~h}$ (Fig. 1). The patients' symptom score was subtracted from the treatment score. By calculating this score, patients were separated into two groups: the adequately and the inadequately treated (Fig. 1). As for the PMI, negative scores were interpreted as inadequate treatment [18]. Based on previous studies, inadequate treatment was interpreted as including both patients not receiving any treatment for their reported symptoms and patients receiving treatment but still reporting moderate or severe symptoms (Fig. 1) [8, 9].

For each symptom, the subgroups of adequately (positive scores or zero) and inadequately treated patients (negative scores) were compared with respect to demographic- and disease-related factors. Mann-Whitney $U$ tests were performed for continuous data, and Fisher's exact tests were performed for categorical data $(2 \times 2$ tables).

Multiple logistic regression analyses were used to examine the association between inadequate treatment and demographic-, as well as disease-related factors. The dependent variable was inadequate versus adequate treatment. Four separate multiple logistic regressions were performed, one for each of the symptoms investigated. Based on clinical experience and the existing literature on prevalence of symptoms and adequacy of treatment, the factors considered for inclusion as independent variables were age [16], discrepancy in symptom scores between health care providers and patients (provider score minus patient score) [19, 24], body mass index (BMI) [25], number of medications administered the past $24 \mathrm{~h}$ (excluding opioids) [25, 26], gender [18], Karnofsky performance status [19], total MMS score [4], time since diagnosis [12, 27], affiliation to department, presence of pain during the past week [6, 27], status of opioid treatment [3, 28], previous or ongoing abuse of alcohol and/or drugs [5, 29], use of chemotherapy during the past $24 \mathrm{~h}$ [30], presence of metastases [19] and cancer diagnosis. Univariate logistic regression analyses were used to screen for an association between these factors and the dependent variable. A factor was considered as a candidate for inclusion in the multiple logistic regression analysis if it was marginally associated with the dependent $(p \leq 0.25)$ [18]. Independent factors considered as candidates after univariate regressions $(p \leq$
0.25) were entered into the backward multiple logistic regression analyses with $F>0.05$ as criterion for removal. All multiple logistic regression models were stratified by country.

The statistical software SPSS for Windows v. 16.0 was used for all statistical analyses except the stratified multiple logistic regressions, which were performed by using the statistical software STATA version 11.0.

\section{Results}

Patients

The mean age was $62 \pm 12$ years, mean Karnofsky performance status was $62 \pm 16$, mean MMS score was $27 \pm 3$, mean time since diagnosis was $33 \pm 47$ months and mean time since initiation of opioid treatment was $5 \pm 11$ months. Genders were equally represented ( $48 \%$ female). Most patients received stable opioid dosing $(81 \%)$ and were hospitalized (78\%). The percentages of patients reporting moderate or severe symptoms were higher among the hospitalized than among outpatients (data not shown). Percentages of patients reporting the symptom intensity as moderate or severe were for constipation $45 \%$, nausea $27 \%$, depression $31 \%$ and poor sleep $32 \%$ (Table 1). Figure 2 shows the intensities of symptoms as reported by patients and health care providers. The distribution of patients with respect to country is given in Table 2 .

\section{Treatment of symptoms}

Although all patients in this study received strong opioids, almost half of them were not given any laxative during the past $24 \mathrm{~h}$ (Table 1). For patients reporting moderate or severe constipation, $41 \%$ and $27 \%$ were not given any laxative treatment. Bulk laxatives were the most commonly administered laxatives (Table 1). Antiemetic drugs were given to approximately $40 \%$ of all patients (Table 1). Thirty-one percent of the patients reporting severe nausea were not treated. Approximately $20 \%$ of patients were prescribed an antidepressant (Table 1). However, $74 \%$ of the patients reporting quite a bit depression and $72 \%$ of those reporting very much depression were not given any medications for symptom relief. Close to $80 \%$ of patients

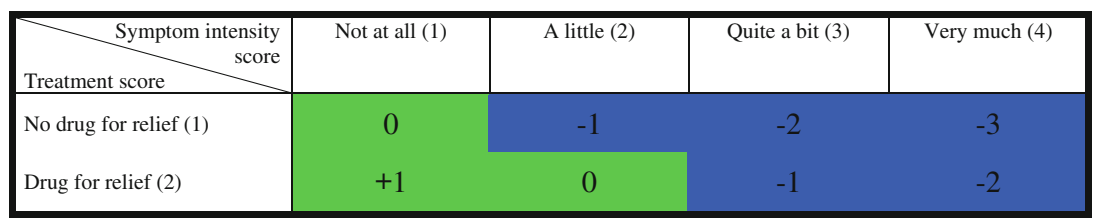

Fig. 1 The relationship between symptom intensity and treatment calculated by subtracting patients' symptom score from treatment score. Green colour symbolizes adequate treatment; blue colour symbolizes inadequate treatment 
Table 1 Symptomatic treatment administered

\begin{tabular}{|c|c|c|c|c|c|c|c|}
\hline \multirow[t]{2}{*}{ Symptom } & \multirow[t]{2}{*}{$\begin{array}{l}\text { Treatment during the past } \\
24 \mathrm{~h}\end{array}$} & \multirow{2}{*}{$\begin{array}{l}\text { Total } \\
(N=2,294)^{\mathrm{a}} \\
N(\%)\end{array}$} & \multicolumn{4}{|c|}{$\begin{array}{l}\text { Symptom intensity among patients self-reporting } \\
(N=1,938)\end{array}$} & \multirow{2}{*}{$\begin{array}{l}\text { Mann-Whitney } \\
U \text { test } \\
\alpha\end{array}$} \\
\hline & & & $\begin{array}{l}\text { Not at all } \\
N(\%)\end{array}$ & $\begin{array}{l}\text { A little } \\
N(\%)\end{array}$ & $\begin{array}{l}\text { Quite a bit } \\
N(\%)\end{array}$ & $\begin{array}{l}\text { Very much } \\
N(\%)\end{array}$ & \\
\hline \multirow[t]{4}{*}{ Constipation } & $\begin{array}{l}\text { No laxative } \\
\text { Laxative }\end{array}$ & $\begin{array}{l}1,099(48.1) \\
1,185(51.9)\end{array}$ & $\begin{array}{l}391(67.1)^{\mathrm{b}} \\
192(32.9)^{\mathrm{b}}\end{array}$ & $\begin{array}{l}251(52.6)^{\mathrm{c}} \\
226(47.4)^{\mathrm{b}}\end{array}$ & $\begin{array}{l}194(40.8)^{\mathrm{c}} \\
281(59.2)^{\mathrm{c}}\end{array}$ & $\begin{array}{l}106(27.0)^{\mathrm{c}} \\
286(73.0)^{\mathrm{c}}\end{array}$ & $<0.001$ \\
\hline & Bulk laxative & $579(49.0)$ & $101(52.6)$ & $122(54.2)$ & $117(41.6)$ & $117(41.1)$ & 0.001 \\
\hline & Stimulant laxative & $261(22.1)$ & $44(22.9)$ & $53(23.6)$ & $75(26.7)$ & $46(16.1)$ & 0.080 \\
\hline & Other laxative & $342(28.9)$ & $47(24.5)$ & $50(22.2)$ & $89(31.7)$ & $122(42.8)$ & $<0.001$ \\
\hline Nausea & $\begin{array}{l}\text { No antiemetic } \\
\text { Antiemetic }\end{array}$ & $\begin{array}{r}1,404(61.5) \\
880(38.5)\end{array}$ & $\begin{array}{l}641(73.4)^{\mathrm{b}} \\
232(26.2)^{\mathrm{b}}\end{array}$ & $\begin{array}{l}325(61.2)^{\mathrm{c}} \\
206(38.8)^{\mathrm{b}}\end{array}$ & $\begin{array}{l}147(43.0)^{\mathrm{c}} \\
195(57.0)^{\mathrm{c}}\end{array}$ & $\begin{array}{r}58(31.2)^{\mathrm{c}} \\
128(68.8)^{\mathrm{c}}\end{array}$ & $<0.001$ \\
\hline Depression & $\begin{array}{l}\text { No antidepressant } \\
\text { Antidepressant }\end{array}$ & $\begin{array}{r}1,833(80.3) \\
451(19.7)\end{array}$ & $\begin{array}{r}544(85.0)^{\mathrm{b}} \\
96(15.0)^{\mathrm{b}}\end{array}$ & $\begin{array}{l}546(79.7)^{\mathrm{c}} \\
139(20.3)^{\mathrm{b}}\end{array}$ & $\begin{array}{l}294(73.7)^{\mathrm{c}} \\
105(26.3)^{\mathrm{c}}\end{array}$ & $\begin{array}{r}138(71.9)^{\mathrm{c}} \\
54(28.1)^{\mathrm{c}}\end{array}$ & $<0.001$ \\
\hline \multirow[t]{5}{*}{ Poor sleep } & $\begin{array}{l}\text { No hypnotic } \\
\text { Hypnotic }\end{array}$ & $\begin{array}{r}1,887(82.6) \\
397(17.4)\end{array}$ & $\begin{array}{l}610(82.8)^{\mathrm{b}} \\
127(17.2)^{\mathrm{b}}\end{array}$ & $\begin{array}{r}482(84.0)^{\mathrm{c}} \\
92(16.0)^{\mathrm{b}}\end{array}$ & $\begin{array}{r}323(78.8)^{\mathrm{c}} \\
87(21.1)^{\mathrm{c}}\end{array}$ & $\begin{array}{r}166(79.4)^{\mathrm{c}} \\
43(20.6)^{\mathrm{c}}\end{array}$ & 0.077 \\
\hline & Barbiturates & $2(0.5)$ & $1(0.8)$ & 0 & $1(1.1)$ & 0 & 0.855 \\
\hline & Benzodiazepine-derivates & $44(10.9)$ & $12(9.4)$ & $8(8.6)$ & $10(11.1)$ & $4(9.3)$ & 0.715 \\
\hline & Benzodiazepine-like & $347(86.3)$ & $113(88.3)$ & $82(88.2)$ & $76(84.4)$ & $39(90.7)$ & 0.741 \\
\hline & Other hypnotics & $9(2.2)$ & $2(1.6)$ & $3(3.2)$ & $3(3.3)$ & 0 & 0.921 \\
\hline
\end{tabular}

Numbers and percentages of untreated and treated patients within each of the symptom intensity groups

Mann-Whitney $U$ tests were performed to investigate whether the numbers of untreated and treated patients varied in relation to symptom intensity

${ }^{a}$ There were missing data for ten patients on treatment yes/no, for 1,112 patients on laxative category and for 1,892 patients on hypnotic drug category

${ }^{\mathrm{b}}$ Adequate treatment

${ }^{\mathrm{c}}$ Inadequate treatment

reporting severe sleeping difficulties were not treated with hypnotics (Table 1). The most common type of hypnotics was benzodiazepine-like drugs. Treatment was more frequently administered for higher intensities of constipation, nausea and depression $(p<0.001)$, whereas no such relationship was found for poor sleep ( $p=0.077$; Table 1).

Almost $60 \%$ of patients were inadequately treated for constipation, depression and poor sleep (defined as treatment score minus symptom score $<0$; Table 2). Of patients reporting nausea, $44 \%$ were classified as inadequately treated.

Characteristics of the inadequately treated and factors associated with inadequate symptom control

The characteristics of inadequately treated patients are shown in Table 2. For all symptoms investigated, patients inadequately treated were characterized by provider underestimation of symptom intensity $(p<0.001)$, lower Karnofsky performance status $(p<0.05)$, hospitalization $(p<0.05)$, more pain $(p<0.05)$ and recent initiation of opioid treatment $(p<0.05$; Table 2$)$. Also, the number of patients inadequately treated varied between countries with for instance fewer patients in Denmark and Iceland, and more patients in Lithuania and Germany being evaluated as inadequately treated (Table 2). Some of the demographic- and diseaserelated factors differed significantly between the adequately and the inadequately treated (Table 2) but were not retained as factors associated with inadequate symptom control in multiple logistic regression (Table 3).

The factors that were marginally associated $(p \leq 0.25)$ with the dependent in univariate analyses (data not shown) were included in the multiple logistic regression analyses. Six factors were retained as associated with inadequate treatment for constipation after multiple logistic regressions (Table 3). In addition to the underestimation of intensity by providers $(p<0.001)$, also lower performance status $(p=$ $0.014)$, recent initiation of opioids $(p=0.029)$ and one or more metastases $(p=0.043)$ increased the risk of inadequate treatment. Patients reporting abuse of alcohol and/or drugs $(p=0.002)$ and patients with gastrointestinal cancer $(p=$ 0.035 ) had lower risk of being inadequately treated for constipation (Table 3).

The risk of being inadequately treated for nausea was increased in younger patients $(p=0.023)$, if health care provider underestimated nausea intensity $(p<0.001)$, if opioid titration was still ongoing $(p=0.018)$ and if the patient had cancer of the female reproductive organs $(p<$ 0.015; Table 3). Patients reporting abuse of alcohol and/or 
Fig. 2 Symptom prevalence and intensity as rated by patients and health care providers (observer)

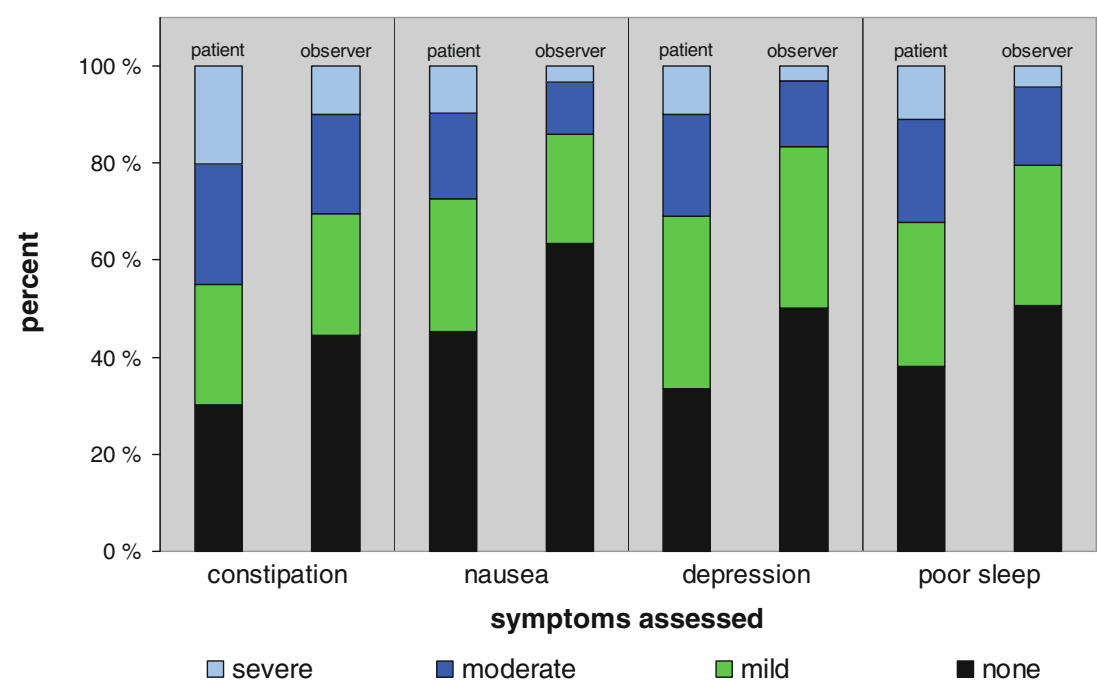

drugs had lower risk of being inadequately treated for nausea ( $p=0.042$; Table 3 ).

More patients were inadequately treated among those who rated their depression as more severe than the health care providers did $(p<0.001)$, had lower BMI $(p=0.043)$, lower performance status $(p<0.001)$, lower total MMS score $(p<0.001)$, were reporting pain during the past week $(p=0.005)$, were still undergoing opioid titration $(p<0.001)$ or had other cancer (e.g. sarcoma, skin or brain tumour; $p=$ 0.034; Table 3).

Patients were more likely to be inadequately treated for poor sleep if they were younger $(p<0.001)$, if health care providers rated the symptom as less severe than the patients $(p<0.001)$, if the patient received fewer medications $(p<$ $0.001)$, if male $(p=0.034)$, if the performance status was lower $(p<0.001)$, if the patient was hospitalized $(p=0.008)$ or had cancer classified as other (e.g. sarcoma, skin or brain tumour; $p=0.004$; Table 3).

\section{Discussion}

The main finding of this study was that constipation, nausea, depression and poor sleep were inadequately controlled in a large number of European cancer patients receiving opioids. Inadequate treatment of all symptoms was associated with symptom underestimation by health care providers. Among the factors associated with inadequate treatment of symptoms were also lower age, lower Karnofsky performance status, recent initiation of opioids, reporting of no abuse and certain cancer diagnoses. Despite advances of symptomatic treatment in cancer care, major challenges remain in developing and implementing effective guidelines for achievement of adequate symptom control.
Interpretation of inadequate treatment

In the present study, the relationship between symptom level and treatment level was utilized to define inadequate treatment. As there was no previous clear-cut definitions, we based our definitions on the existing literature which was two studies on nausea $[9,16]$, one study on constipation [8] and several studies on adequacy of pain management [17]. Still, at least three aspects of the subtraction approach (treatment level minus symptom level) need to be addressed. First, symptoms may differ in respect to whether lack of treatment for patients reporting 'a little' symptoms should be interpreted as inadequate treatment. Whereas opioid-treated patients reporting a little constipation clearly should have laxatives [3, 4], physicians are probably more reluctant to prescribe hypnotics for patients reporting a little sleeping difficulties. To investigate how defining also patients reporting 'a little' symptoms as adequately treated would influence the findings, logistic regressions were performed, showing that most factors persisted (constipation five of six, nausea two of four, depression four of five and poor sleep three of five). Second, inadequate treatment included both patients not treated and patients reporting symptoms despite treatment (e.g. wrong drug, insufficient dose and true treatmentresistant symptoms). It might be argued that the term inadequate treatment is inappropriate for treatment-resistant symptoms, but previous studies have shown that many patients within this group actually receive suboptimal doses or the wrong drug $[8,9,11]$. Third, there could be specific clinical reasons for not administering treatment, such as interactions, allergy or patient barriers. Therefore, future studies should segregate such specific reasons from lack of good clinical practice. 
Table 2 Characteristics of patients receiving adequate and inadequate treatment

\begin{tabular}{|c|c|c|c|c|c|c|c|c|c|c|}
\hline \multicolumn{3}{|c|}{ Inadequate treatment of symptoms } & \multicolumn{2}{|c|}{ Constipation } & \multicolumn{2}{|c|}{ Nausea } & \multicolumn{2}{|c|}{ Depression } & \multicolumn{2}{|c|}{ Poor sleep } \\
\hline & & & No & Yes & No & Yes & No & Yes & No & Yes \\
\hline \multicolumn{3}{|l|}{ Age } & 61.5 & 61.7 & 62.1 & 61.1 & 62.2 & 61.2 & 63.6 & $60.2 * * *$ \\
\hline \multicolumn{3}{|c|}{ Assessment discrepancy (provider-patient) } & 0.1 & $-0.7^{* * *}$ & 0.0 & $-0.9^{* * *}$ & 0.1 & $-0.7 * * *$ & 0.2 & $-0.7 * * *$ \\
\hline \multicolumn{3}{|l|}{ Body mass index } & 23.8 & 23.7 & 23.8 & 23.6 & 24.1 & $23.5^{* *}$ & 23.9 & 23.6 \\
\hline \multirow{2}{*}{\multicolumn{2}{|c|}{ Number of medications, except opioids }} & & 6.9 & $6.6^{*}$ & 7.0 & $6.5^{* *}$ & 6.8 & 6.7 & 6.9 & $6.6^{*}$ \\
\hline & & $N^{\mathrm{a}}$ & $\%$ Ina & late & $\%$ In & late & $\%$ Ina & late & $\%$ Ina & rate \\
\hline \multirow[t]{2}{*}{ Gender } & Male & 1,013 & 58 & & $41^{* *}$ & & 59 & & $59^{*}$ & \\
\hline & Female & 925 & 58 & & 47 & & 60 & & 55 & \\
\hline \multirow{2}{*}{$\begin{array}{l}\text { Karnofsky performance } \\
\text { status }\end{array}$} & $\leq 80$ & 1,824 & $59 *$ & & $45^{*}$ & & $61 * * *$ & & $58 * *$ & \\
\hline & $>80$ & 111 & 48 & & 32 & & 39 & & 44 & \\
\hline \multirow{2}{*}{$\begin{array}{l}\text { Mini mental state, total } \\
\text { score }\end{array}$} & $\leq 23$ & 258 & $52 *$ & & $37 *$ & & $66^{*}$ & & 55 & \\
\hline & $>23$ & 1,568 & 58 & & 45 & & 58 & & 58 & \\
\hline \multirow{2}{*}{$\begin{array}{l}\text { Time since diagnosis } \\
\text { (months) }\end{array}$} & $\leq 3$ & 404 & 57 & & 44 & & 62 & & 60 & \\
\hline & $>3$ & 1,367 & 59 & & 43 & & 59 & & 57 & \\
\hline \multirow[t]{2}{*}{ Department } & Hospitalized & 1,518 & $59 *$ & & $46^{* *}$ & & $63 * * *$ & & $59 * *$ & \\
\hline & Outpatients & 420 & 53 & & 37 & & 47 & & 51 & \\
\hline \multirow{2}{*}{$\begin{array}{l}\text { Pain intensity (the past } \\
\text { week) }\end{array}$} & No & 124 & $48 *$ & & $29^{* * * *}$ & & $39 * * *$ & & $27 * * *$ & \\
\hline & Yes & 1,804 & 59 & & 45 & & 61 & & 59 & \\
\hline \multirow[t]{2}{*}{ Status of opioid treatment } & Initiation, titration & 356 & $65^{* *}$ & & $53^{* * *}$ & & $67^{* *}$ & & $64 * *$ & \\
\hline & Stable dosing & 1,566 & 56 & & 42 & & 58 & & 56 & \\
\hline \multirow[t]{2}{*}{ Abuse alcohol and/or drugs } & No & 1,813 & $59 *$ & & $45^{*}$ & & 59 & & 57 & \\
\hline & Yes & 115 & 47 & & 34 & & 61 & & 61 & \\
\hline \multirow[t]{2}{*}{ Chemotherapy the past $24 \mathrm{~h}$} & No & 1,643 & 57 & & 44 & & 60 & & 56 & \\
\hline & Yes & 295 & 62 & & 43 & & 58 & & 61 & \\
\hline \multirow[t]{2}{*}{ Metastases } & None & 332 & $50 * *$ & & 47 & & 59 & & 57 & \\
\hline & One or more & 1,605 & 60 & & 44 & & 59 & & 57 & \\
\hline \multirow[t]{10}{*}{ Cancer diagnosis $^{\mathrm{b}}$} & Breast & 269 & 63 & & 46 & & 57 & & $51^{*}$ & \\
\hline & $\begin{array}{l}\text { Female reproductive } \\
\operatorname{organ}^{c}\end{array}$ & 145 & 59 & & $58 * * *$ & & 53 & & 59 & \\
\hline & Gastrointestinal & 444 & $50 * * *$ & & 41 & & 59 & & 57 & \\
\hline & Haematological & 113 & 59 & & 45 & & 56 & & 62 & \\
\hline & Head and neck & 105 & 51 & & 40 & & 65 & & 53 & \\
\hline & Lung & 347 & 62 & & 44 & & 61 & & 59 & \\
\hline & Other & 169 & 63 & & 48 & & 65 & & $68^{*}$ & \\
\hline & Prostate & 230 & 60 & & 44 & & $53^{*}$ & & 54 & \\
\hline & Unknown origin & 51 & 54 & & 37 & & 57 & & 54 & \\
\hline & Urological & 139 & 63 & & 41 & & 66 & & 57 & \\
\hline Country & Denmark & 29 & $21 * * *$ & & $24 *$ & & $21 * * *$ & & 41 & \\
\hline & Finland & 30 & 67 & & 32 & & 50 & & 47 & \\
\hline & Germany & 274 & 57 & & $54 * *$ & & $85^{* * *}$ & & $74 * * *$ & \\
\hline & Greece & 5 & 60 & & 40 & & 25 & & 40 & \\
\hline & Iceland & 145 & $39 * * *$ & & $35^{*}$ & & $32 * * *$ & & $30 * * *$ & \\
\hline & Italy & 400 & $68 * * *$ & & $27^{* * * *}$ & & 57 & & $62 *$ & \\
\hline & Lithuania & 54 & $78^{* *}$ & & 50 & & $80^{* *}$ & & $78 * *$ & \\
\hline & Norway & 477 & 61 & & $58 * * *$ & & 58 & & 55 & \\
\hline & Sweden & 119 & $46^{* *}$ & & $54 *$ & & $76^{* * *}$ & & $43 * *$ & \\
\hline & Switzerland & 114 & 58 & & 45 & & $77 * * *$ & & $75 * * *$ & \\
\hline & UK & 291 & 54 & & 40 & & $42 * * *$ & & $50 *$ & \\
\hline
\end{tabular}

Comparison of the patients interpreted as adequately treated (positive scores or zero after subtracting the symptom score from the treatment score) and inadequately treated (negative scores). Continuous data are reported as mean and compared by Mann-Whitney $U$ tests. Categorical data are reported as percentages within each subcategory and compared by Fisher's exact test

${ }^{*} p<0.05 ;{ }^{* *} p<0.01 ; * * * p<0.001$

${ }^{a} N$ is the absolute number of patients in each group. The sum and numbers may vary for symptoms due to missing data

${ }^{\mathrm{b}}$ Some patients had more than one cancer diagnosis; consequently, the sum of percentages is larger than 100

${ }^{\mathrm{c}}$ Female reproductive organ is short for cancer of the female reproductive organs 
Table 3 Factors significantly associated with inadequate symptom control

\begin{tabular}{|c|c|c|c|c|c|}
\hline & & Constipation & Nausea & Depression & Poor sleep \\
\hline \multirow[t]{3}{*}{$\operatorname{Age}^{a}$} & $\mathrm{OR}^{\mathrm{b}}$ & & 0.78 & & 0.97 \\
\hline & $95 \% \mathrm{CI}$ & & 0.62 to 0.97 & & 0.96 to 0.98 \\
\hline & $p$ & & 0.023 & & $<0.001$ \\
\hline \multirow[t]{3}{*}{ Assessment discrepancy (provider-patient score) } & $\mathrm{OR}^{\mathrm{b}}$ & 0.22 & 0.13 & 0.16 & 0.23 \\
\hline & $95 \% \mathrm{CI}$ & 0.18 to 0.26 & 0.10 to 0.17 & 0.12 to 0.20 & 0.19 to 0.27 \\
\hline & $p$ & $<0.001$ & $<0.001$ & $<0.001$ & $<0.001$ \\
\hline \multirow[t]{3}{*}{ Body mass index } & $\mathrm{OR}^{\mathrm{b}}$ & & & 0.97 & \\
\hline & $95 \% \mathrm{CI}$ & & & 0.95 to 1.00 & \\
\hline & $p$ & & & 0.043 & \\
\hline \multirow[t]{3}{*}{ Number of medications, excluding opioids } & $\mathrm{OR}^{\mathrm{b}}$ & & & & 0.93 \\
\hline & $95 \% \mathrm{CI}$ & & & & 0.90 to 0.96 \\
\hline & $p$ & & & & $<0.001$ \\
\hline Gender & $\mathrm{OR}^{\mathrm{b}}$ & & & & 0.74 \\
\hline 0: male & $95 \% \mathrm{CI}$ & & & & 0.60 to 0.92 \\
\hline 1: female & $p$ & & & & 0.006 \\
\hline Karnofsky performance status & $\mathrm{OR}^{\mathrm{b}}$ & 0.59 & & 0.39 & 0.48 \\
\hline $0: \leq 80$ & $95 \% \mathrm{CI}$ & 0.38 to 0.90 & & 0.26 to 0.58 & 0.31 to 0.75 \\
\hline $1:>80$ & $P$ & 0.014 & & $<0.001$ & 0.001 \\
\hline Mini mental state, total score & $\mathrm{OR}^{\mathrm{b}}$ & & & 0.65 & \\
\hline $0: \leq 23$ & $95 \% \mathrm{CI}$ & & & 0.47 to 0.91 & \\
\hline $1:>23$ & $p$ & & & 0.011 & \\
\hline Department & $\mathrm{OR}^{\mathrm{b}}$ & & & & 0.70 \\
\hline 0 : hospital & $95 \% \mathrm{CI}$ & & & & 0.54 to 0.91 \\
\hline 1: outpatient & $p$ & & & & 0.008 \\
\hline Pain (intensity past week) & $\mathrm{OR}^{\mathrm{b}}$ & & & 1.96 & \\
\hline 0 : none & $95 \% \mathrm{CI}$ & & & 1.22 to 3.13 & \\
\hline 1: little, quite, very & $p$ & & & 0.005 & \\
\hline Status of opioid treatment & $\mathrm{OR}^{\mathrm{b}}$ & 0.73 & 0.73 & 0.73 & \\
\hline 0 : initiation, titration & $95 \% \mathrm{CI}$ & 0.55 to 0.97 & 0.55 to 0.96 & 0.53 to 1.00 & \\
\hline 1: stable dosing & $p$ & 0.029 & 0.025 & 0.047 & \\
\hline Abuse alcohol and/or drug & $\mathrm{OR}^{\mathrm{b}}$ & 0.51 & 0.62 & & \\
\hline $0:$ no & $95 \% \mathrm{CI}$ & 0.33 to 0.78 & 0.40 to 0.98 & & \\
\hline 1: yes & $p$ & 0.002 & 0.042 & & \\
\hline Metastases & $\mathrm{OR}^{\mathrm{b}}$ & 1.31 & & & \\
\hline 0 : none & $95 \% \mathrm{CI}$ & 1.01 to 1.71 & & & \\
\hline \multirow[t]{2}{*}{ 1: one or more } & $p$ & 0.043 & & & \\
\hline & Type & Gastrointestinal & Female reproductive organ ${ }^{\mathrm{c}}$ & Other & Other \\
\hline Cancer diagnosis & $\mathrm{OR}^{\mathrm{b}}$ & 0.77 & 1.69 & 1.64 & 1.78 \\
\hline $0:$ no & $95 \% \mathrm{CI}$ & 0.61 to 0.98 & 1.11 to 2.57 & 1.04 to 2.59 & 1.20 to 2.64 \\
\hline 1: yes & $p$ & 0.035 & 0.015 & 0.034 & 0.004 \\
\hline
\end{tabular}

The dependent variable was inadequate versus adequate treatment. Negative scores after subtraction of the patient's symptom score from the treatment score were recoded as one and represented inadequate treatment, whereas zero or positive scores were recoded as zero and represented adequate treatment

OR odds ratio, $C I$ confidence interval

${ }^{a}$ For nausea, the age variable was dichotomized into patients $\leq 60$ and $>60$ years [30]. For constipation, depression and poor sleep, the age variable was continuous (years)

${ }^{\mathrm{b}}$ An odds ratio above 1 reflects more under-treatment

${ }^{\mathrm{c}}$ Female reproductive organ is short for cancer of the female reproductive organs 


\section{Characterization of treatment}

Inadequate treatment of constipation, nausea, depression and poor sleep was widespread in European cancer patients (Table 1). In line with previous findings, constipation was inadequately controlled in $60 \%$ of patients [1, 8]. A recent study concluded that inadequate treatment of nausea in advanced cancer is now infrequent, as prescription of antiemetics has increased from $32 \%$ in 1986 to $68 \%$ in 2008 [9]. This conclusion is challenged by the present study, showing that only $38 \%$ of patients were given an antiemetic and that nearly half of nauseated patients were inadequately treated. Of patients reporting moderate or severe depression, $70 \%$ did not receive an antidepressant. The number of patients fulfilling the criteria of a depressive disorder was unknown in the present study, but the high number of untreated may reflect a lack of effective communication and clearly established diagnostic and therapeutic procedures, which are known barriers to prescription of antidepressants [6]. Approximately $20 \%$ of patients received a hypnotic drug in the present study, which was lower than the range (58$85 \%$ ) previously described as under-prescription [10, 13], but in line with a more recent study among cancer patients attending outpatient clinics where approximately $20 \%$ received sleeping pills [27].

Inadequate symptom control: characteristics of patients and factors contributing

The presence of inadequate treatment differed between countries. Variations in use of symptomatic treatment across European countries have been documented previously [2] and may reflect the lack of well-designed, randomized controlled trials and multinational guidelines on symptomatic treatment. In addition, the variability may reflect differences in opioid availability [31], the range of different services providing supportive care and the differences between patient populations admitted to these services [32]. The observed differences between countries are of interest and should be explored further. However, with the above-mentioned influences and because this study only included a selection of centres in each country, we are cautious in our interpretation of the observed country-related differences.

Underestimation of symptom intensity by providers was consistently associated with inadequate treatment of all symptoms investigated. Underestimation of pain is a barrier to pain management $[18,19]$, and the present findings indicate that underestimation may hamper adequate treatment of other symptoms as well. This finding is of particular importance for cancer patients not able to report their own symptoms.

The factors associated with inadequate treatment of constipation were compatible with clinical experience. Patients with lower Karnofsky performance status have reduced physical activity, which makes constipation more difficult to treat [4]. Constipation encountered during opioid titration can be a dose-limiting adverse effect [3]. Patients that abuse alcohol often have diarrhoea, and constipation may therefore be less problematic [29]. Patients with metastatic disease can be constipated for reasons that need other treatment approaches than antiemetic drugs (e.g. metastases compressing the spinal cord and malignant bowel obstruction) [4]. In patients with gastrointestinal cancer, the lower risk of inadequate treatment is perhaps a result of an increased focus on treatment of gastrointestinal symptoms.

Lower age and cancer of the female reproductive organs were associated with inadequate control of nausea, which may reflect that both younger patients and women are more prone to nausea [30]. The association with opioid titration possibly reflects that nausea can be difficult to treat in this phase and that antiemetics may be retained because tolerance to nausea often develops quite fast [3]. The association with 'no abuse' could reflect that emesis may be more easily controlled in patients abusing alcohol [5].

Regarding inadequate treatment of depression, the association with other (rarer) cancer diagnoses was difficult to explain. Still, most of the factors fitted with clinical experience as depression is closely related to lower BMI [25] and lower Karnofsky performance status [33], as it is difficult to separate depression from declining cognitive functions [21] and as pain and depression can be more difficult to treat when they appear together [6].

The association between inadequate treatment of poor sleep and lower age may reflect that physicians fear dependency in the younger and therefore are more reluctant to prescribe hypnotics [7] or that prescription of hypnotics is more common in patients predisposed to sleep difficulties (e.g. the elderly and women) [13]. Age and gender-related differences in use of hypnotics were not present in a previous study [26]. The association with number of other medications may reflect that providers were aware that hypnotics often contribute to polypharmacy [25, 26]. Inadequately treated poor sleep in patients with lower performance status may reflect that bedridden, deteriorating patients need other treatment than hypnotics [7]. The association with hospitalization was not unexpected, as the hospitalized are more ill, receive more concomitant treatments and have disruptions of their habitual lifestyles in general [7]. The association with other (rarer) cancer diagnoses was difficult to explain.

\section{Implications}

The approach for evaluation of inadequate treatment applied in this study could be used at a group level as a quality indicator for treatment of symptoms in advanced 
cancer [15] and could increase comparability between future studies. The present findings indicate that management of symptoms other than pain may be subject to some of the same barriers as pain treatment [1, 17, 18, 34]. Future research addressing specific barriers towards symptomatic treatment in cancer care would be of interest.

\section{Limitations}

To our knowledge, this is the largest study addressing adequacy of symptomatic treatment in European cancer patients. However, we recognize that the study have some limitations. First, treatments administered were registered for the past $24 \mathrm{~h}$, whereas symptoms were reported for the past week. However, that treatment was not initiated at the study day despite patient reports of moderate or severe symptoms for 1 week strengthen the evidence for a lack of adequate initiation of treatment. Second, all details about the treatments (time since initiation, type and dosage and administration route) were not collected. For the analyses, we chose to use the presence or lack of symptomatic treatment. It is difficult to evaluate the adequacy of choice of specific medications and dosages because there is no gold standard (recommendations) representing the correct treatment. Third, data on numbers and characteristics of patients not approached or declining to take part in the study was not obtained. However, a large number of patients were included, and their characteristics were as expected for a cancer pain patient cohort. Finally, separate studies are needed to address the accuracy, validity and reliability of the definitions of inadequate treatment used in this study.

\section{Conclusions}

Inadequate treatment of symptoms, either no treatment or ineffective treatment, was frequent among European cancer patients. Patients rating their symptoms as more severe than the providers, with lower Karnofsky performance status or undergoing opioid titration were at particular risk for inadequate treatment. The subset of demographic- and diseaserelated factors associated with inadequate treatment varied between the symptoms investigated. The health care system needs to implement guidelines for symptomatic treatment, health care providers need to improve their symptom assessment and patients characterized by the presence of certain risk factors for inadequate treatment need special attention to provide better symptom control in cancer care.

Acknowledgements This work was supported by grants from the Norwegian University of Science and Technology, the European Palliative Care Research Collaborative, the European Commission's Sixth Framework Programme and the Norwegian Research Council. The authors are grateful to the researchers involved in The European Pharmacogenetic Opioid Study (EPOS).
Disclosures None.

Open Access This article is distributed under the terms of the Creative Commons Attribution Noncommercial License which permits any noncommercial use, distribution, and reproduction in any medium, provided the original author(s) and source are credited.

\section{References}

1. van den Beuken-van Everdingen MHJ, de Rijke JM, Kessels AG, Schouten HC, van Kleef M, Patijn J (2009) Quality of life and non-pain symptoms in patients with cancer. J Pain Symptom Manag 38:216-233

2. Laugsand E, Kaasa S, de Conno F, Hanks G, Klepstad P (2009) Intensity and treatment of symptoms in 3,030 palliative care patients: a cross-sectional survey of the EAPC Research Network. J Opioid Manag 5:11-21

3. McNicol E, Horowicz-Mehler N, Fisk RA, Bennett K, GialeliGoudas M, Chew PW, Lau J, Carr D (2003) Management of opioid side effects in cancer-related and chronic noncancer pain: a systematic review. J Pain 4:231-256

4. Larkin PJ, Sykes NP, Centeno C, Ellershaw JE, Elsner F, Eugene B, Gootjes JRG, Nabal M, Noguera A, Ripamonti C, Zucco F, Zuurmond WWA (2008) The management of constipation in palliative care: clinical practice recommendations. Palliat Med 22:796-807

5. Rhodes VA, McDaniel RW (2001) Nausea, vomiting, and retching: complex problems in palliative care. CA Cancer $\mathrm{J}$ Clin 51:232-248

6. Stiefel R, Die Trill M, Berney A, Olarte JM, Razavi A (2001) Depression in palliative care: a pragmatic report from the Expert Working Group of the European Association for Palliative Care. Support Care Cancer 9:477-488

7. Savard J, Morin CM (2001) Insomnia in the context of cancer: a review of a neglected problem. J Clin Oncol 19:895-908

8. Droney J, Ross J, Gretton S, Welsh K, Sato H, Riley J (2008) Constipation in cancer patients on morphine. Support Care Cancer $16: 453-459$

9. Greaves J, Glare P, Kristjanson LJ, Stockler M, Tattersall MH (2009) Undertreatment of nausea and other symptoms in hospitalized cancer patients. Support Care Cancer 17:461-464

10. Stiefel FC, Kornblith AB, Holland JC (1990) Changes in the prescription patterns of psychotropic-drugs for cancer-patients during a 10-year period. Cancer 65:1048-1053

11. Wood GJ, Shega JW, Lynch B, Von Roenn JH (2007) Management of intractable nausea and vomiting in patients at the end of life- "I was feeling nauseous all of the time ... nothing was working". JAMA 298:1196-1207

12. Dy SM, Lorenz KA, Naeim A, Sanati H, Walling A, Asch SM (2008) Evidence-based recommendations for cancer fatigue, anorexia, depression, and dyspnea. J Clin Oncol 26:3886-3895

13. Lee K, Cho M, Miaskowski C, Dodd M (2004) Impaired sleep and rhythms in persons with cancer. Sleep Med Rev 8:199-212

14. Kaasa S, Loge JH, Fayers P, Caraceni A, Strasser F, Hjermstad MJ, Higginson I, Radbruch L, Haugen DF (2008) Symptom assessment in palliative care: a need for international collaboration. J Clin Oncol 26:3867-3873

15. Pasman HR, Brandt HE, Deliens L, Francke AL (2009) Quality indicators for palliative care: a systematic review. J Pain Symptom Manag 38:145-156 
16. Reuben DB, Mor V (1986) Nausea and vomiting in terminal cancer patients. Arch Intern Med 146:2021-2023

17. Deandrea S, Montanari M, Moja L, Apolone G (2008) Prevalence of undertreatment in cancer pain. A review of published literature. Ann Oncol 19:1985-1991

18. Cleeland CS, Gonin R, Hatfield AK, Edmonson JH, Blum RH, Stewart JA, Pandya KJ (1994) Pain and its treatment in outpatients with metastatic cancer. N Engl J Med 330:592-596

19. Larue F, Colleau S, Brasseur L, Cleeland C (1995) Multicenter study of cancer pain and its treatment in France. Br Med J 310:1034-1037

20. Folstein MF, Folstein SE, McHugh PR (1975) Mini-mental state. A practical method for grading the cognitive state of patients for the clinician. J Psychiatr Res 12:189-198

21. Pereira J, Hanson J, Bruera E (1997) The frequency and clinical course of cognitive impairment in patients with terminal cancer. Cancer 79:835-842

22. Karnofsky D, Abelmann W, Craver L, Burchenal JH (1948) The use of nitrogen mustard in the palliative treatment of cancer. Cancer 1:634-656

23. Aaronson N, Ahmedzai S, Bergman B, Bullinger M, Cull A, Duez N (1993) The European Organization for Research and Treatment of Cancer QLQ-C30 - a quality-of-life instrument for use in international clinical trials in oncology. J Natl Cancer Inst 85:365376

24. Velikova G, Booth L, Smith AB, Brown PM, Lynch P, Brown JM, Selby PJ (2004) Measuring quality of life in routine oncology practice improves communication and patient well-being: a randomized controlled trial. J Clin Oncol 22:714-724
25. Extermann M, Hurria A (2007) Comprehensive geriatric assessment for older patients with cancer. J Clin Oncol 25:1824-1831

26. Derogatis LR, Feldstein M, Morrow G, Schmale A, Schmitt M, Gates C, Murawski B, Holland J, Penman D, Melisaratos N, Enelow AJ, Adler LM (1979) Survey of psychotropic-drug prescriptions in an oncology population. Cancer 44:1919-1929

27. Davidson JR, MacLean AW, Brundage MD, Schulze K (2002) Sleep disturbance in cancer patients. Soc Sci Med 54:1309-1321

28. Cherny N, Ripamonti C, Pereira J, Davis C, Fallon M, McQuay H, Mercadante S, Pasternak G, Ventafridda V (2001) Strategies to manage the adverse effects of oral morphine: an evidence-based report. J Clin Oncol 19:2542-2554

29. Bode C, Bode JC (1997) Alcohol's role in gastrointestinal tract disorders. Alcohol Health Res World 21:76-83

30. Foubert J, Vaessen G (2005) Nausea: the neglected symptom? Eur J Oncol Nurs 9:21-32

31. Cherny NI, Baselga J, de Conno F, Radbruch L (2010) Formulary availability and regulatory barriers to accessibility of opioids for cancer pain in Europe: a report from the ESMO/EAPC opioid policy initiative. Ann Oncol 21:615-626

32. Kaasa S, Torvik K, Cherny N, Hanks G, de Conno F (2007) Patient demographics and centre description in European palliative care units - a cross sectional survey of the European Association for Palliative Care (EAPC) research network. Palliat Med 21:15-22

33. Bukberg J, Penman D, Holland JC (1984) Depression in hospitalized cancer-patients. Psychosom Med 46:199-212

34. Pargeon KL, Hailey BJ (1999) Barriers to effective cancer pain management: a review of the literature. J Pain Symptom Manag $18: 358-368$ 